\title{
Simulation of a Hall Effect Thruster with Krypton Propellant
}

\author{
Horatiu C. Dragnea* \\ University of Michigan, Ann Arbor, MI, 48109, USA \\ Alejandro Lopez Ortega ${ }^{\dagger}$ \\ Jet Propulsion Laboratory, Pasadena, CA, 91109, USA \\ Iain D. Boyd ${ }^{\ddagger}$ \\ University of Michigan, Ann Arbor, MI, 48109, USA
}

\begin{abstract}
The multi-fluid framework Hall2De is updated to perform simulations of Hall thrusters operating with krypton propellant. A series of eight simulations of the NASA-300M thruster are performed with both xenon and krypton and the implementation is validated by comparison to experimental measurements from NASA Glenn Research Center. For all operating points the computed thrust matches experimental values to within $10 \%$. Krypton gas generates a specific impulse value between 10 and 16 percent higher than xenon propellant, while producing thrust values between 15 and 25 percent lower than in the xenon simulations. These results are consistent with a back-of-the-envelope theoretical calculation. Next, an unshielded H6 thruster, which has not yet been operated experimentally with a krypton propellant, is also simulated. A $28 \%$ lower mass flow rate of krypton gas is required to operate the thruster at the same $6 \mathrm{~kW}$ power level as with xenon propellant. The performance trends observed are consistent with the NASA-300M thruster simulations. Further, the singly charged ion current fraction for xenon is lower than for krypton, while for the higher charge species the trend is reversed. This behavior is explained by the relative differences in cross-sections between the different ionization processes for the same gas.
\end{abstract}

\section{Nomenclature}

\begin{tabular}{|c|c|c|c|}
\hline$\eta_{\text {mass }}$ & mass efficiency & $m_{\text {ion }}$ & ion mass \\
\hline$e$ & elementary charge & $\dot{m}$ & mass flow rate \\
\hline$\vec{E}$ & electric field & $T_{e}$ & electron temperature \\
\hline$f_{e i}$ & electron-ion collision frequency & $v$ & velocity magnitude \\
\hline$f_{\text {en }}$ & electron-neutral collision frequency & $V_{d}$ & discharge voltage \\
\hline$f_{a}$ & anomalous collision frequency & & \\
\hline$F_{\text {thrust }}$ & thrust & & \\
\hline$g_{0}$ & gravitational acceleration at sea level & & \\
\hline$i_{\text {charge }}$ & charge number & & \\
\hline$I_{\text {beam }}$ & beam current & & \\
\hline$I_{d}$ & discharge current & & \\
\hline$I_{s p}$ & specific impulse & & \\
\hline$\vec{j}_{e}$ & electron current density & & \\
\hline$n_{i}$ & ion number density & & \\
\hline$n_{n}$ & neutral number density & & \\
\hline
\end{tabular}

*PhD Candidate, Department of Aerospace Engineering, Ann Arbor, MI, 48109, USA, AIAA Student Member.

$\dagger$ Technologist, Jet Propulsion Laboratory, Pasadena, CA, 91107, USA.

${ }^{\ddagger}$ James E. Knott Professor, Department of Aerospace Engineering, Ann Arbor, MI, 48109, USA, AIAA Fellow. 


\section{Introduction}

Hall effect thrusters (HETs) have a long history of over five decades of development and use on spacecraft for stationkeeping and orbit-raising. While the typical choice of propellant for HETs has been xenon, several studies have considered the use of krypton as an alternative ${ }^{1,2,3}$. Using krypton can significantly lower the costs of testing: as of May 2017, xenon gas was approximately 45 times more expensive than krypton.

Although most simulation work has focused on xenon propellant thrusters, there have been previous efforts to evaluate the use of krypton gas. In 2001 Garrigues $^{4}$ used a 1D hybrid model to investigate thruster performance of the SPT-100 with krypton gas, and found that for the same voltage and mass flow rate similar values of thrust may be obtained between xenon and krypton, but a lower efficiency is observed for the krypton gas (30\% versus $40 \%$ for xenon). In $2008 \mathrm{Yim}^{5}$ applied a 2D hydrodynamic model to study krypton operation on the NASA-173Mv1 HET. However the model did not capture the peaks of electric field and electron temperature accurately since the thermal conductivity term in the electron energy conservation equation was neglected. Both previous efforts focused only on the thruster channel. The present work is the first attempt to simulate both thruster and plume with krypton propellant using a 2D axisymmetric model and validate the results with experimental measurements.

Several updates are made to include krypton as a propellant into the fluid code Hall2De ${ }^{6,7,8}$, and they are described in Section II. A first series of simulations is performed on the NASA-300M thruster (Section III) for validation purposes: the setup is explained in Section A, while the results are shown in Section C. Further, the H6 unshielded (H6US) thruster is simulated (Section IV) both with xenon and krypton, with the setup described in Section A and results in Section B. Conclusions are discussed in Section V and future work is suggested in Section VI.

\section{Hall2De Updates}

The simulation tool Hall2De has been developed at the Jet Propulsion Laboratory over the past decade for the purpose of studying HETs. The computational grid is aligned with the magnetic field, and a typical domain includes both the thruster channel and a large plume that extends several channel lengths downstream. The model is axisymmetric, with the radial zero coordinate located at the thruster centerline.

Different models are used for each of the plasma species: neutrals, ions and electrons. Under the assumption of free molecular flow, the neutral particle density and velocity distributions are computed with a view-factor algorithm $^{6}$. A hydrodynamic approach is used to model the ions, and they are divided into multiple populations, based on energy. The ions generated upstream of the acceleration region are part of the high energy population, while the ions generated downstream will form the low energy population. Thus, in most cases the HET physics can be modeled with two populations of ions. In addition to solving separate continuity and momentum equations for each population, each charge state is also resolved independently. The different energy populations and charged states interact with each other through ionization, charge exchange and elastic collisions. Finally, the electrons are modeled using a fluid approach. The Generalized Ohm's law in vector form in the directions parallel and perpendicular to the magnetic field lines, coupled with charge conservation and plasma quasi-neutrality yield the plasma potential, while the electron temperature is computed from an energy conservation equation.

In order to use krypton propellant in the simulation, several updates are implemented, related to the properties of the new propellant gas. The ionization cross-sections of krypton affect the ionization rate which results in different numbers of neutral and charged species than in the xenon case. Further, the ionization potential plays a direct role in the electron energy equation, by changing the electron energy losses.

Table 1 provides a comparison of the atom mass and the ionization threshold energies for krypton, compared to xenon. While the $\mathrm{Kr}$ mass is $64 \%$ that of xenon, the ionization potential for krypton is consistently higher 
than for xenon, for up to the fourth charge state.

Table 1. Propellant gas properties.

\begin{tabular}{lllr} 
& Xe & $\mathrm{Kr}$ & \% Kr of Xe value \\
\hline Mass (a.m.u.) & 131.3 & 83.8 & 63.8 \\
Ionization potential 1 (eV) & 12.1 & 14.0 & 115.7 \\
Ionization potential 2 (eV) & $12.1+21.2$ & $14.0+24.4$ & 115.3 \\
Ionization potential 3 (eV) & $12.1+21.2+31.1$ & $14.0+24.4+35.8$ & 115.2 \\
Ionization potential 4 (eV) & $12.1+21.2+31.1+50.0$ & $14.0+24.4+35.8+50.9$ & 109.4
\end{tabular}

Energy loss mechanisms are implemented through the introduction of a collision cross-section corresponding to each process. Elastic scattering cross-sections are presented in Section A for krypton, and compared to the existing implementation of xenon cross-sections used in Hall2De. The krypton values are consistently lower, with a maximum difference of $42 \%$ lower than the xenon values. Electron-impact ionization processes are also considered, and the cross sections are shown in Section B. Krypton cross-sections are lower than those of xenon for all ionization processes, and the maximum percent difference for each process is presented in Section B. Charge exchange (CEX) cross-sections are discussed in Section C, and in this case the values reported for krypton are only at most $11 \%$ lower than those for xenon. We note that the CEX and elastic scattering cross-sections are 10 to 100 times larger than the ionization cross-sections, depending on the ionization process. For all processes considered, the xenon cross-sections are larger than for krypton at a given energy, and this increases the probability of each process occurring. However, considering results from kinetic theory, ${ }^{9}$ we recall that the collision event probability is also proportional to the mean relative velocity between particles, which as shown in Eq. 1 is in turn proportional to the inverse square root of the mass. Throughout the present work we provide explanations of various simulation results based on the differences in cross-sections, but the effect of mass is discussed as well. Since krypton atoms are lighter than those of xenon, the effect of mass is to reduce the differences in collision outcomes that would be observed based on cross-section values alone.

$$
\langle C\rangle \propto \sqrt{\frac{8 k T}{\pi m}}
$$

\section{A. Elastic Scattering}

The elastic scattering cross-sections are plotted in Figure 1 for both xenon and krypton. Data for xenon is selected from two sources: Register ${ }^{13}$ for energies between 1 and $4 \mathrm{eV}$, and Nickel ${ }^{12}$ for values above 4 $\mathrm{eV}$. Several authors reported consistent values of krypton elastic cross-sections, however the most recent publications are selected. Thus krypton data from Yuan ${ }^{10}$ is used for energies between 0 and $7.5 \mathrm{eV}$, while the data reported by Wagenaar ${ }^{11}$ is used for energies between 7.5 and $750 \mathrm{eV}$. The values for krypton are lower than for xenon throughout the entire energy range, with a maximum difference of $42 \%$.

\section{B. Electron-impact Ionization}

Three charged states of the propellant gas are included in the simulation, and we consider all six ionization processes that may results in singly, doubly or triply charged ions.

The ionization cross-sections for electron impact ionization from the ground state up to the three charged states are shown in Figure 2. The xenon cross-sections for all three cases are extracted from Rejoub. ${ }^{15}$ For all three processes the cross-sections from Wetzel have an uncertainty of $15 \%$, while those reported by Rejoub only $5 \%$. 


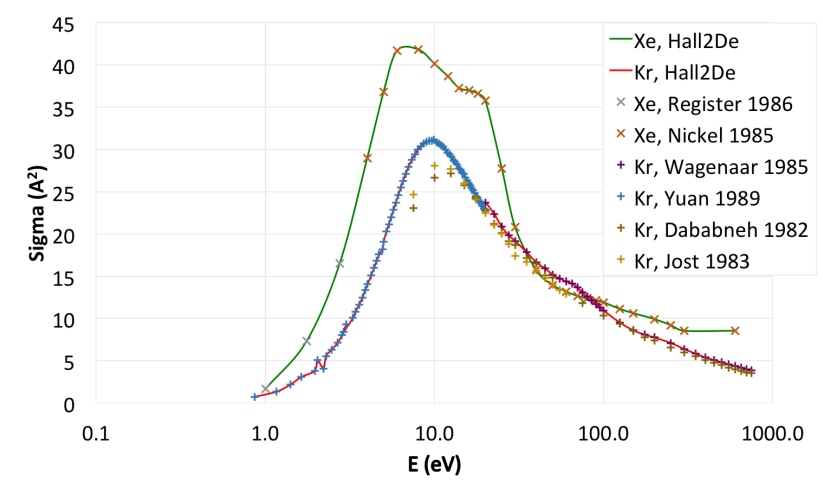

Figure 1. Krypton elastic scattering cross-sections.

For the single ionization process, data from Wetzel ${ }^{14}$ is used between 13 and $15 \mathrm{eV}$, while between 15 and $1000 \mathrm{eV}$, data from Rejoub ${ }^{15}$ is implemented. The cross-sections for krypton are lower than for xenon, with a maximum difference of $26 \%$. When accounting for the different mass of the two gases, the difference between the probability of single ionization for krypton is only $7.5 \%$ lower than that of xenon undergoing the same process.

For the double ionization process, between 40 and $45 \mathrm{eV}$ data from Wetzel ${ }^{14}$ is used, and from 45 to $1000 \mathrm{eV}$, the cross-section values are taken from Rejoub's work ${ }^{15}$. For this process the krypton cross-sections are at most $43 \%$ lower than those for xenon, however when considering the mass ratio of the gases, the ionization collision probability value for krypton is $29 \%$ lower than that of xenon.

For triple ionization from the ground state, the data from Rejoub ${ }^{15}$ is used in the entire range $(90-1000 \mathrm{eV})$. In this case the cross-section values for krypton are significantly smaller than for xenon, with a maximum difference of $89 \%$. Considering the probability of the triple ionization process to occur, due to the effect of mass the process is $86 \%$ less likely to occur than for xenon.

Next, the cross-sections for ionization of singly charged ions are shown in Figure 3, while Figure 4 shows the cross sections for doubly charged to triply charged ion transitions. Xenon cross-sections from Bell ${ }^{16}$ are used for the single to double ionization process, while unpublished data from Borovik is used for the remainder of the ionization processes.

For krypton, the authors could only identify data from Tinschert ${ }^{17}$, so cross-sections from that source are used in all the above mentioned cases for the entire energy range presented. For low energies there are large uncertainties in the cross-section values $(\approx 100 \%)$, however the uncertainties reduce rapidly when looking at higher energy ions. For single to double, the large uncertainties occur between 15 and $23 \mathrm{eV}$, for double to triple between 21 and $23 \mathrm{eV}$, and for single to triple between 50 and $56.6 \mathrm{eV}$.

The krypton cross-sections are lower than the xenon values for all three cases. For the singly to doubly charged ionization process the maximum difference is $50 \%$, for doubly to triply charged it is $37 \%$ and for singly to triply charged the percent difference is $79 \%$. When considering the probability of these ionization events to occur, the trend remains the same: for krypton the singly to doubly charged transition is $38 \%$ less likely to occur than for xenon, for doubly to triply charged it is $20 \%$ less likely to occur, and finally, for singly to triply charged it is $73 \%$ less likely to occur than for the xenon case.

\section{Charge Exchange}

The charge-exchange collision process is implemented by considering a collision cross-section, as shown in Fig. 5. Since the cross-sections for collisions with doubly and triply charged ions are obtained by scaling Fig. 5 by the charge number, only data for collisions between neutrals and singly charged ions is shown. The curve 


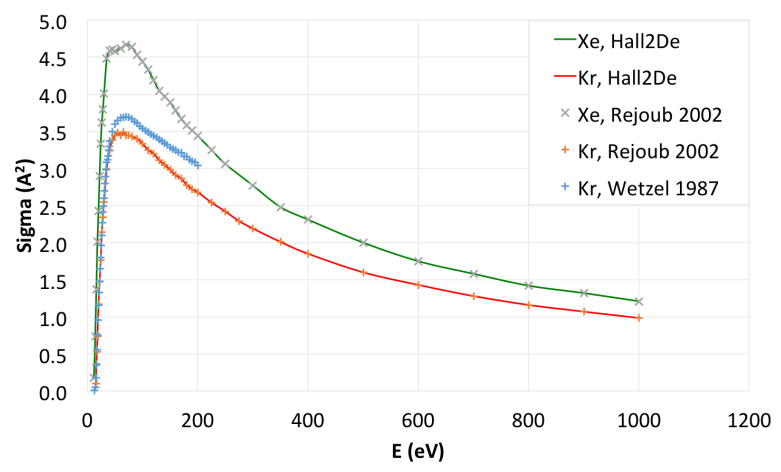

(a) Ground to singly charged.

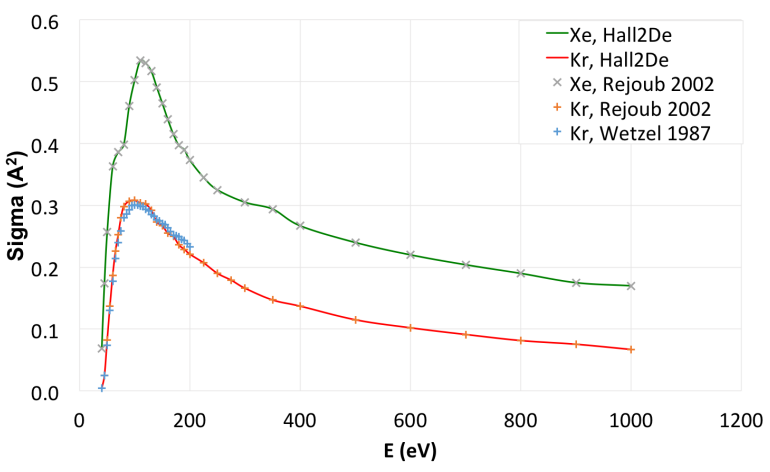

(b) Ground to doubly charged.

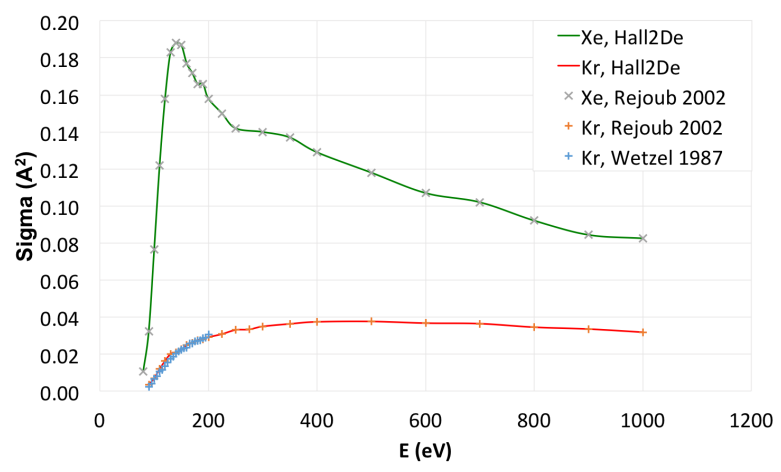

(c) Ground to triply charged.

Figure 2. Krypton ionization cross-sections from the ground state.

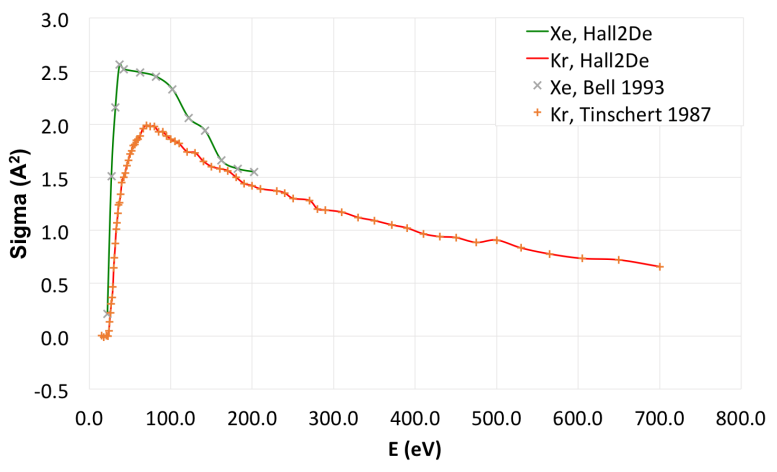

(a) Singly to doubly charged.

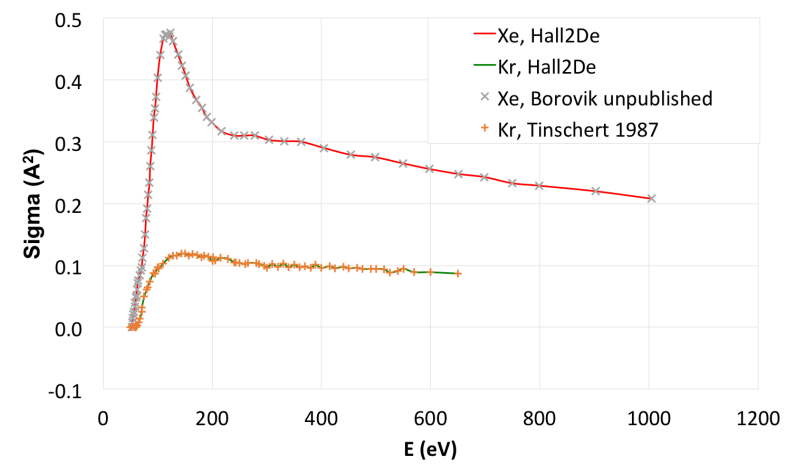

(b) Singly to triply charged.

Figure 3. Ionization cross-sections from singly charged ions. 


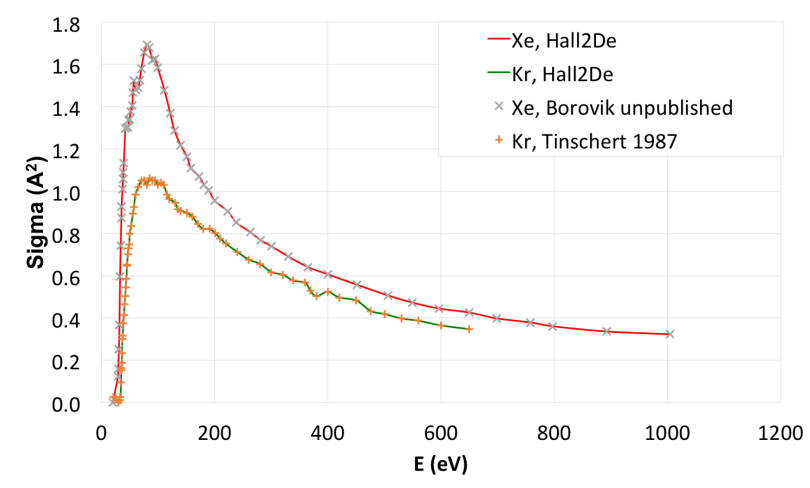

Figure 4. Cross-sections for the doubly to triply charged ionization process.

for krypton is obtained from Hause, ${ }^{18}$ and the values are consistently lower than the xenon cross-sections for the entire energy range, with a maximum difference of $11 \%$. However, when accounting for the effects of mass on collision probability, we notice the opposite trend: the krypton collision is $10 \%$ more likely to occur.

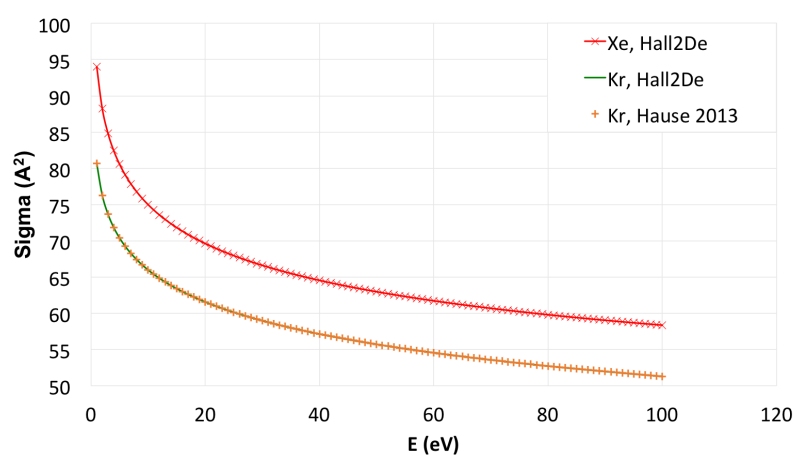

Figure 5. Cross-sections for the charge exchange process (neutral $\leftrightarrow$ singly charged ion).

\section{Experimental Validation for NASA-300M}

The krypton implementation must be validated against experimental data, and the NASA-300M thruster is selected for this purpose due to the availability of experimental measurements ${ }^{19}$ and a previous Hall2De simulation for one operating point using $x^{2}{ }^{20}{ }^{20}$ The NASA-300M is a $20-\mathrm{kW}$ class Hall thruster that was designed, fabricated, and assembled at NASA Glenn Research Center in 2004-2005, and further characterized in 2010-2011. Finally, in 2013 the principles of magnetic shielding ${ }^{21}$ were applied to produce the NASA-300MS ${ }^{22}$. In the present work, the unshielded thruster is simulated.

\section{A. Simulation Setup}

The starting point for the comparison is a previous xenon simulation, performed for the $400 \mathrm{~V}, 50 \mathrm{~A}$ operating condition. The electron collision frequency profile is informed by experimental measurements of the temperature and thrust. Values at the channel centerline are presented in Fig. 6. Figure 6(a) shows a comparison of the electron temperature profile obtained from the simulation and experiment in the near-field plume of the thruster, as well as the value of the computed plasma potential. Since measurements inside the channel may perturb the plasma parameters and result in an axial shift of as much as 15-20\% of the channel length $^{23}$, the comparison inside the channel is not shown. The electron temperature obtained from Hall2De lies within the experimental error, for up to $1.5 \mathrm{z} / \mathrm{L}$. The computed thrust value is $975 \mathrm{mN}$, only $5.3 \%$ lower than the measured value of $1030 \mathrm{mN}$. Next, the electron-ion, electron-neutral and anomalous 
collision frequencies are plotted in Fig. 6(b). The anomalous collision frequency increases sharply at the channel exit, but begins to decrease further in the plume.

The magnetic field strength was adjusted between different operational conditions in the laboratory, so the collision frequency profile is also expected to change. However, since the magnetic field values were only available for the $400 \mathrm{~V}$ and $50 \mathrm{~A}$ xenon gas operating condition, the electron collision frequency profile, magnetic field topology and magnitude from this particular test case are used in all simulations of the 300M thruster. While this approximation may produce discrepancies between simulation and experiment, the goal is to qualitatively evaluate the results of the krypton simulation by comparison with both values from krypton experiments, and xenon results.

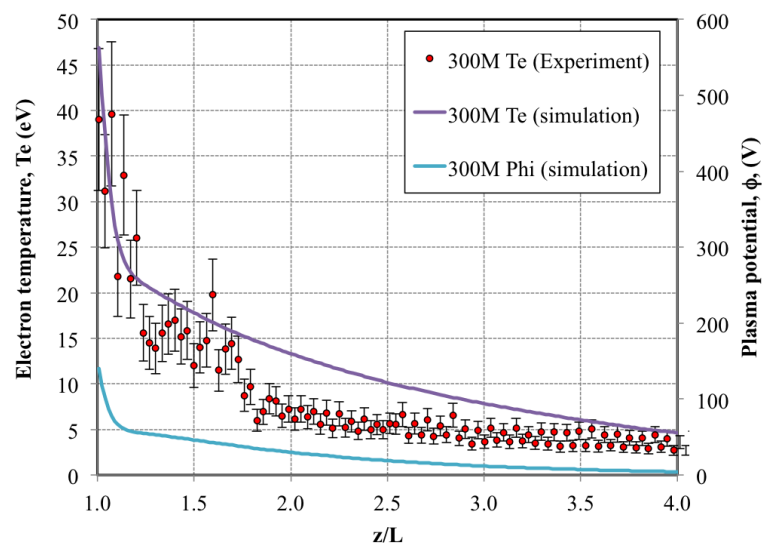

(a) Plasma properties.

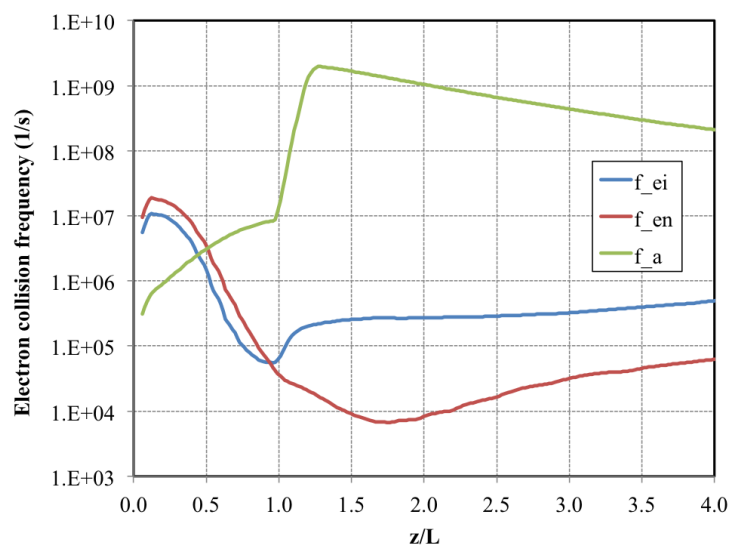

(b) Electron collision frequencies.

Figure 6. Simulation results at $400 \mathrm{~V}, 50 \mathrm{~A}$ with xenon propellant.

A set of eight Hall2De simulations are prepared for both xenon and krypton, and the operating conditions are summarized in Table 2. Over the entire range, the krypton mass flow rate used is between 27.6 and 35.5 percent lower than in the case of xenon.

Table 2. NASA-300M operating conditions.

\begin{tabular}{ccc|rrr} 
& & \multicolumn{3}{|c}{$\dot{m}(\mathrm{mg} / \mathrm{s})$} \\
$\mathrm{P}_{d}(\mathrm{~kW})$ & $\mathrm{V}_{d}(\mathrm{~V})$ & $\mathrm{I}_{d}(\mathrm{~A})$ & $\mathrm{Xe}$ & $\mathrm{Kr}$ & $\%$ difference Kr vs. Xe \\
\hline 10 & 200 & 50.0 & 43.8 & 31.4 & -27.9 \\
10 & 300 & 33.3 & 30.3 & 22.0 & -28.2 \\
10 & 400 & 25.0 & 26.7 & 17.2 & -27.6 \\
10 & 500 & 20.0 & 20.0 & 14.4 & -28.2 \\
15 & 300 & 50.0 & 43.8 & 31.4 & -28.2 \\
20 & 400 & 50.0 & 43.8 & 31.4 & -27.6 \\
20 & 500 & 40.0 & 35.7 & 25.8 & -35.5 \\
20 & 600 & 33.3 & 30.3 & 22.0 & -28.2
\end{tabular}

\section{B. Theoretical Estimate}

Before analyzing the simulation data, a simplified thruster performance calculation estimate is performed. The goal is to compute the thrust (Eq. 2) and specific impulse (Eq. 3) for the two propellant gases by only considering the discharge voltage and discharge current. The estimate for thrust requires a value for mass 
flow rate and a velocity magnitude, while the specific impulse is dependent on the thrust and mass flow rate.

$$
\begin{gathered}
F_{\text {thrust }}=\dot{m} \cdot v \\
I_{s p}=\frac{F_{\text {thrust }}}{g_{0} \cdot \dot{m}}
\end{gathered}
$$

Starting with the definition of mass efficiency in Eq. 4 we can express the mass flow rate as a function of beam current, ion mass, and charge. Assuming that the beam current can be estimated as approximately $75 \%$ of the discharge current, setting the mass efficiency to a value of 1 , and only considering singly charged ions provides a means of estimating the mass flow rate directly from the discharge current.

$$
\eta_{\text {mass }}=\frac{I_{\text {beam }} \times m_{\text {ion }}}{i_{\text {charge }} \times e \times \dot{m}}
$$

The velocity magnitude value needed in the thrust computation may be derived from an energy conservation principle. By neglecting all other forms of energy, we set the kinetic energy equal to the electric potential energy, and thus derive the expression in Eq. 5. Note that we are using the value of the discharge voltage without accounting for the cathode fall. The potential reduction due to the cathode fall may be considered as part of the thruster efficiency. It is difficult to ascertain how the cathode fall value for krypton compares to that of xenon for each operating condition, so in order to produce a prediction based solely on known data, we compute the velocity magnitude as described here.

$$
v=\sqrt{\frac{2 V_{d} e}{m_{\text {ion }}}}
$$

Therefore equations 4 and 5 can be combined with Eq. 2 and Eq. 3 to provide thrust and specific impulse estimates based only on the thruster operating point as defined by its discharge current and voltage.

Applying the above algorithm for the operating condition discussed in Section A at $50 \mathrm{~A}$ and $400 \mathrm{~V}$ for both xenon and krypton yields the results summarized in Table 3 . The percent difference between the krypton and xenon estimates for all three parameters is independent of operating condition, so the trends shown in this example are expected to hold at all operating conditions. Thus when comparing the Hall2De simulations, the krypton cases should produce a higher specific impulse but lower thrust than when using xenon propellant.

Table 3. NASA-300M performance estimates for $I_{d}=50 \mathrm{~A}$, and $V_{d}=400 \mathrm{~V}$.

\begin{tabular}{l|rrr} 
& $\mathrm{Xe}$ & $\mathrm{Kr}$ & $\%$ difference Kr vs. Xe \\
\hline$\dot{m}(\mathrm{mg} / \mathrm{s})$ & 51.0 & 32.6 & -36.2 \\
$F_{\text {thrust }}(\mathrm{mN})$ & 1240 & 988 & -20.1 \\
$I_{s p}(\mathrm{~s})$ & 2470 & 3090 & 25.2
\end{tabular}

\section{Results}

In order to provide a global comparison of the various operating conditions, the specific impulse (Eqn. 3) obtained from simulation is plotted against the experimental values ${ }^{19}$ in Figs. 7(a) and 7(b) for xenon and krypton, respectively. The simulation values are plotted with hollow orange symbols, while the measurements are shown in solid blue. A different symbol is used for each voltage value: a triangle for $600 \mathrm{~V}$, a square for $500 \mathrm{~V}$, a circle for $400 \mathrm{~V}$, a rhombus for $300 \mathrm{~V}$, and a nabla symbol for $200 \mathrm{~V}$. When there are multiple data points available at the same voltage, they are joined together by a dashed line. A hollow green symbol shows the simulation data obtained previously by Mikellides. ${ }^{20}$

As expected from the reduced order model in Section B, for the same voltage and discharge current, the krypton propellant produces higher specific impulse than xenon, in both simulation and experiment. For the simulation values, the increase is between 10 and 16 percent, while the back-of-the-envelope calculation 
predicted an increase of $25 \%$. The discrepancy is due to the lower than one mass efficiency of the thruster. Further, while keeping the discharge power constant, increasing the voltage will produce higher specific impulse and this trend holds for both gases. This effect results from a combination of lower discharge current (if keeping the power level constant), and lower mass flow rate for krypton.

Figure 8 shows the thrust values from simulation and measurement for xenon propellant (Fig. 8(a)) and krypton (Fig. 8(b)). The same plotting conventions as in Fig. 7 are applied. For all operating conditions, xenon produces a $15 \%$ to $25 \%$ higher value of thrust than krypton, which is consistent with the $20 \%$ lower krypton value that is expected from the back-of-the-envelope calculation.

Since specific impulse is derived from thrust by using Eq. 3, the error analysis will only focus on thrust. For xenon, the maximum discrepancy between simulation and experiment occurs at $20 \mathrm{~kW}$ and $400 \mathrm{~V}$, where the thrust value from Hall2De is $5.5 \%$ lower than the measurement, thus Fig. 8(a) confirms good agreement with the experimental data.

For krypton, the maximum error is at the $10 \mathrm{~kW}$ and $200 \mathrm{~V}$ operating point: the computed thrust is higher than the measurement by $9.9 \%$. The discrepancies observed between simulation and experiment may be due to the assumption that the magnetic field differences and the uncertainties in the electron transport due to the lack of experimental validation at other conditions are not too large. Indeed, the model produces values within less than $10 \%$ of the experimental values, therefore the assumption is reasonable. However these differences may be reduced further by obtaining the exact magnetic field magnitudes for each operating condition. In addition, if plasma parameter measurements became available for each operating point, a more physical and experimentally informed electron collision frequency profile may be identified, which in turn would improve the agreement between simulation results and experiment. Another factor that may help reduce the error in thrust to the levels observed for xenon, would also be the availability of cross-section data with higher accuracy at low energies.

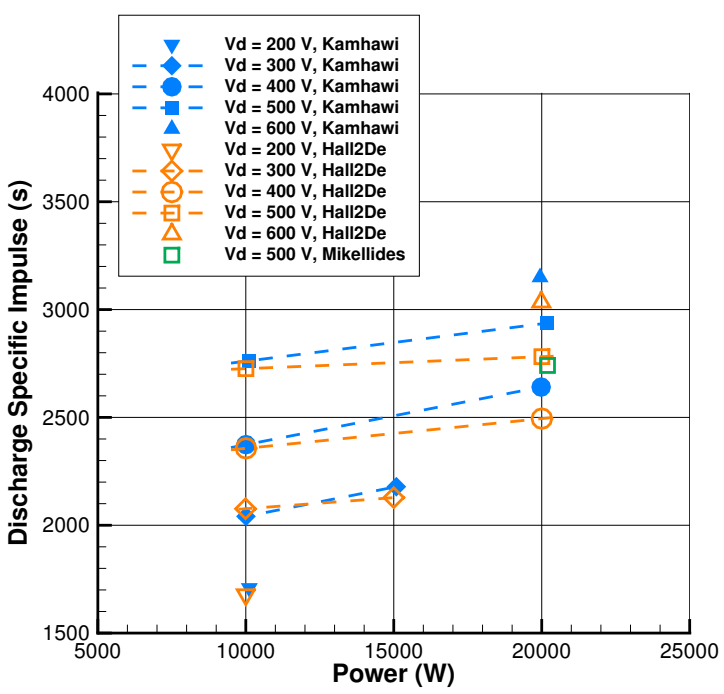

(a) Xenon.

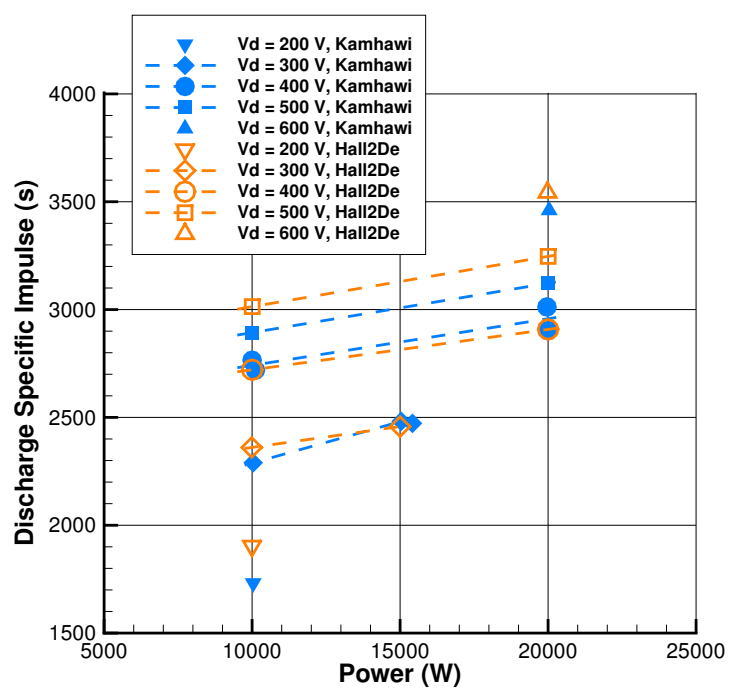

(b) Krypton.

Figure 7. Specific impulse from simulation and experiment. 


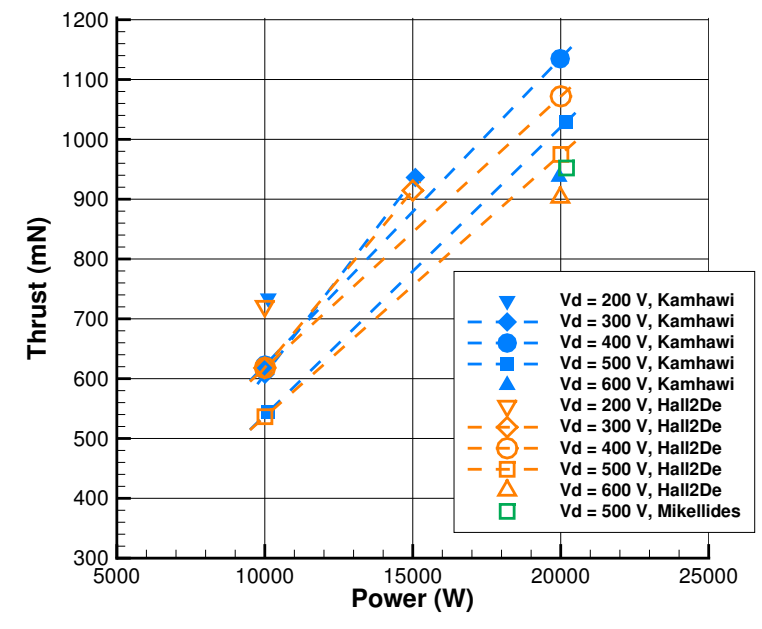

(a) Xenon.

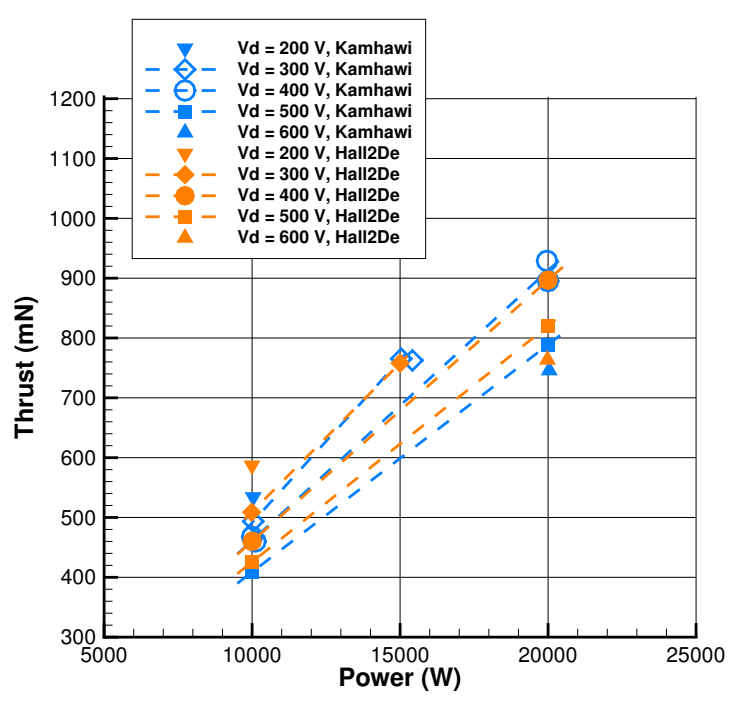

(b) Krypton.

Figure 8. Thrust from simulation and experiment.

\section{Application to H6US}

The H6US thruster was developed and characterized through a joint effort by NASA, the University of Michigan and the Air Force Research Laboratory (AFRL) between 2007 and 2008. It is a $6 \mathrm{~kW}$ device with a throttling range between $100-600 \mathrm{mN}$ and 1000-3000 s specific impulse ${ }^{24-27}$. In 2011-2012 the H6 HET was used for a proof of concept development of magnetic shielding ${ }^{21}$, at which point the original thruster was dubbed the H6US, and the magnetically shielded device H6MS ${ }^{28-31}$.

\section{A. Simulation Setup}

A baseline simulation is prepared for the H6US with xenon propellant, operating at $6 \mathrm{~kW}$ and $300 \mathrm{~V}$ at a mass flow rate of $19.7 \mathrm{mg} / \mathrm{s}$. Next, a simulation with krypton gas is set up that uses the flow rate, magnetic field topology and magnitude from the xenon case. In addition, since there is no experimental guidance available, the electron anomalous collision frequency profile from the xenon simulation is also used for the krypton propellant. The full computational simulation domain extends axially to a value of $10.25 \mathrm{z} / \mathrm{L}$, and radially to a value of $7.25 \mathrm{r} / \mathrm{L}$, however, for illustration purposes, the figures are cropped to maximum values of $4 \mathrm{z} / \mathrm{L}$ and $4 \mathrm{r} / \mathrm{L}$, respectively.

Upon completing the simulation, the computed anode current value is $28.8 \mathrm{~A}$, which implies that the thruster is operating at $8.64 \mathrm{~kW}$, and not $6 \mathrm{~kW}$ as in the xenon case. Thus a third simulation is prepared, where the krypton flow rate is set to $14.1 \mathrm{mg} / \mathrm{s}$. This value is computed from the definition of mass efficiency, shown previously in Eq. 4. The beam current value is found by fixing the discharge power to $6 \mathrm{~kW}$, the voltage to $300 \mathrm{~V}$, and assuming $I_{\text {beam }}=75 \% I_{d}$. The mass efficiency is assumed to be the same as in the $19.7 \mathrm{mg} / \mathrm{s}$ krypton simulation, and that value is 0.992 .

Note that the reduced mass flow rate for krypton is $28.4 \%$ lower than in the xenon simulation, which falls within the range of values used in the 300M experiments (Table 2, final column). However, the percent difference in flow rate between krypton and xenon is $8 \%$ smaller than the prediction made in Section B. The xenon flow rate used in the H6US simulation is $19.7 \mathrm{mg} / \mathrm{s}$, while the prediction from Eq. 4 is $20.58 \mathrm{mg} / \mathrm{s}$. The back-of-the-envelope calculation presented in Section B assumed only singly charged ions, and including higher charged species while keeping the efficiency constant will result in a reduced mass flow rate. Since the H6US simulation includes doubly and triply charged ions, the presence of these higher charge states explains the difference in flow rate. 


\section{B. Results}

Table 4 provides a summary of the simulation results for the $\mathrm{H} 6$ thruster. The anode current values computed by the code are shown for the three test cases. While the first krypton case yields a power level of $8.64 \mathrm{~kW}$, the second krypton case where the mass flow rate is adjusted to lower the power gives $5.73 \mathrm{~kW}$, showing that the scaling is successful. Closer agreement may be achieved by repeating the process and using the new value of efficiency obtained from the $14.1 \mathrm{mg} / \mathrm{s}$ simulation.

The thruster performance parameters are shown in the table: thrust and specific impulse. The thrust value is $14.8 \%$ higher than for xenon in the first krypton case, and $18.9 \%$ lower in the second. As expected, when operating at similar power levels, the thruster using a propellant that has a smaller atom and a higher ionization potential should produce a lower value of thrust. However, since the mass flow rate is lower and this is inversely proportional to the specific impulse, a higher $I_{s p}$ is observed in both $\mathrm{Kr}$ cases. Thus, when using the same flow rate as xenon, a $14.8 \%$ higher $I_{s p}$ is computed, while using a reduced mass flow rate produces a value that is $13.3 \%$ higher. Both trends in thrust and specific impulse are consistent with the back-ofthe-envelope estimate from Section B. While the percent difference in thrust between xenon and krypton is similar in value to the $20 \%$ predicted in Table 3, the increase in specific impulse for the krypton case is not as high as expected (25\%), and this is due to the less than one value of mass efficiency from the simulation.

Furthermore, the table shows the current fractions for singly, doubly and triply charged ions. For single ions, the xenon current fraction is lower than for krypton, while for multiply charged ions, the xenon current fractions are higher than for krypton. These results are expected, considering the cross-section values presented previously in Section B. When comparing the magnitude of different ionization cross-sections, the ground to singly charged values are the largest for both xenon and krypton. However, when comparing the ground to singly charged and ground to doubly charged transition, the maximum cross section decrease is $89 \%$ for xenon, and $91 \%$ for krypton. Further, when looking into the percent decrease between the singly charged to triply charged transition, the cross section decreases by $96 \%$ for xenon, and by $99 \%$ for krypton. This suggests that relative to the ground to singly charged transition, xenon ground to doubly charged and ground to triply charged transitions are more likely to occur than for krypton (the cross-sections do not decrease as much), however the relative percent differences between xenon and krypton are small.

When looking at the ground to singly charged versus the single to doubly charged transition, we notice a significant difference. For xenon the maximum percent difference is $45 \%$, versus $99 \%$ for krypton. This suggests that when comparing the two processes, for xenon we expect to see the production of more double ions that originate from the single to double ionization process than for krypton, and this may help explain the difference in doubly charged ion current fraction between the two gases seen in Table 4.

Finally, when comparing the ratio of ground to singly charged against singly charged to triply charged, the xenon propellant cross-sections decrease by $90 \%$ while for krypton by $97 \%$. Also, the ratio of ground to doubly charged versus doubly charged to triply charged transition cross-sections decreases by $65 \%$ for xenon and $70 \%$ for krypton. Combined, these ratios suggest that the xenon cross-sections decrease less than the krypton ones when compared to the lower level ionization processes. In turn this implies that we should expect a lower ratio of krypton triple ions than xenon triple ions when compared to the other two ion populations.

All of the arguments presented above regarding the ratio of ion currents are based on the cross-section values, and more specifically the maximum percent change between cross sections. Since these comparisons illustrate changes in cross-sections for the same species, and the ion mass does not change, the percent difference in collision probabilities will be the same as the percent change in collision frequencies. A more detailed statistical analysis may be performed in the future, however, experimental measurements from a retarding potential analyzer (RPA) will be necessary to fully validate the current fractions computed with Hall2De.

Figures 9-15 show comparisons between the xenon and krypton simulations at similar power levels. The electron temperature distribution is qualitatively similar between the two cases, as shown in Fig. 9. Since 
Table 4. Simulation results.

\begin{tabular}{lrrr} 
Species & $\mathrm{Xe}$ & $\mathrm{Kr}$ & $\mathrm{Kr}$ \\
\hline Flow rate $(\mathrm{mg} / \mathrm{s})$ & 19.7 & 19.7 & 14.1 \\
Anode current $(\mathrm{A})$ & -21.1 & -28.8 & -19.1 \\
Thrust $(\mathrm{mN})$ & 412 & 473 & 334 \\
$I_{s p}(\mathrm{~s})$ & 2200 & 2530 & 2420 \\
Current fraction + & 0.798 & 0.870 & 0.896 \\
Current fraction ++ & 0.186 & 0.126 & 0.100 \\
Current fraction +++ & 0.016 & 0.005 & 0.004
\end{tabular}

the thruster is operating at similar power levels in both cases, the Joule heating term from the energy equation $\left(\vec{E} \cdot \vec{j}_{e}\right)$ is expected to have similar magnitudes for the two propellants, and this is a dominant effect within the thruster channel.

However, in the near-field plume, the temperature values decrease more rapidly for krypton than for xenon. Since the electric field and electron current density both diminish in the plume, this region is no longer dominated by the effects of Joule heating, but by the thermal conductivity and ionization loss terms. The thermal conductivity term decreases dramatically in the plume for both xenon and krypton, as seen in Fig. 10. The ionization cross-sections are consistently larger for xenon than krypton, and the ionization potential of krypton is higher than that of xenon. The combination of these physical properties make xenon easier to ionize, but this process occurs within the thruster channel. Additionally, CEX cross-section values are an order of magnitude larger than the ionization cross-sections, and this effect will be dominant in the plume. Krypton showed a larger probability to undergo charge-exchange collisions than xenon so it is likely to have a larger population of slow krypton neutrals with a large residence time. In addition, Fig. 12 confirms that the neutral number density of krypton in the near plume is higher than that of xenon. As shown in Section B, slower particles of lower charge number have higher ionization cross-sections, therefore a large population of slow krypton neutrals may be undergoing a significant number of ionizations that may lead to the rapid decrease in electron temperature that we observe in the plume. This hypothesis is also supported by recent measurements from AFRL by Hargus ${ }^{32}$ that suggest that latent krypton ionization occurs farther downstream than in the case for xenon.

The plasma potential distribution is also qualitatively similar inside the channel. However, higher potential values are seen in the xenon near-field plume, as expected since the electron temperature is also higher in that region than in the krypton case. A similar trend is also reflected in the number densities of charged ions with maximum energies of up to $250 \mathrm{eV}$ (fluid 1): Fig. 13 for singly charged, Fig. 14 for doubly charged and Fig. 15 for triply charged. The beams of high density ionized gas observed in the xenon case are also contributing to the higher thrust observed for this propellant.

The singly charged ion species (Fig. 13) density shows the largest differences between xenon and krypton inside the channel and that is due to the higher ground to singly charged ionization probability. When considering a comparison of the doubly charged ion species (Fig. 14), we observe larger differences between xenon and krypton, with the krypton showing lower density values throughout the entire domain. A similar trend is also true for the triply charged ions shown in Fig. 15. These observations are consistent with the ion current fractions reported in Table 4, which show that the xenon singly charged current fraction is lower than for krypton, while for the higher charge states the trend is reversed. 


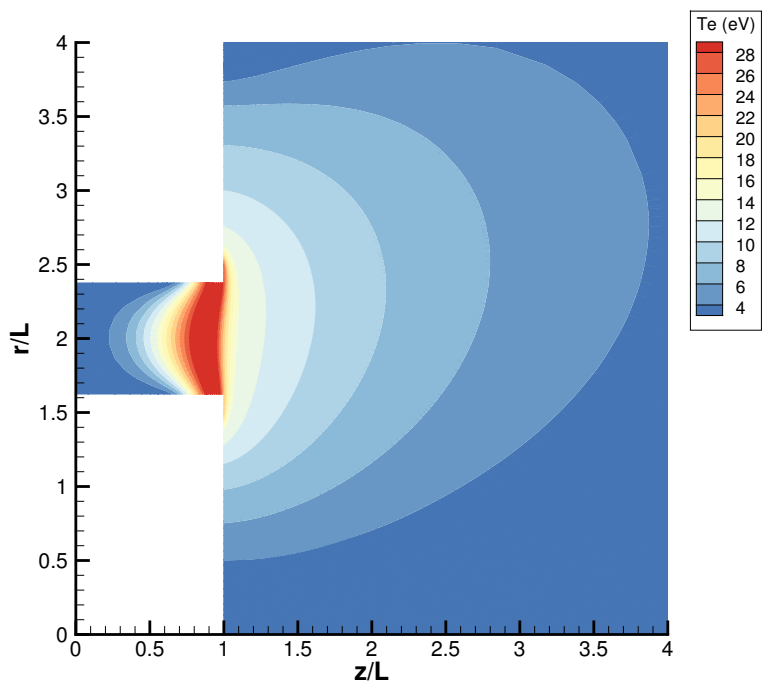

(a) Xenon $\dot{m}=19.7 \mathrm{mg} / \mathrm{s}$.

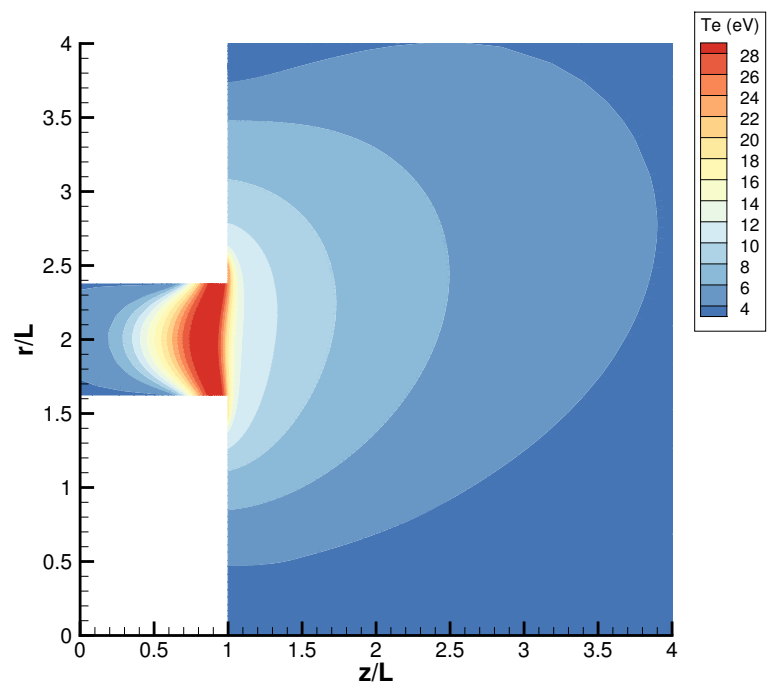

(b) Krypton, $\dot{m}=14.1 \mathrm{mg} / \mathrm{s}$.

Figure 9. Electron temperature.

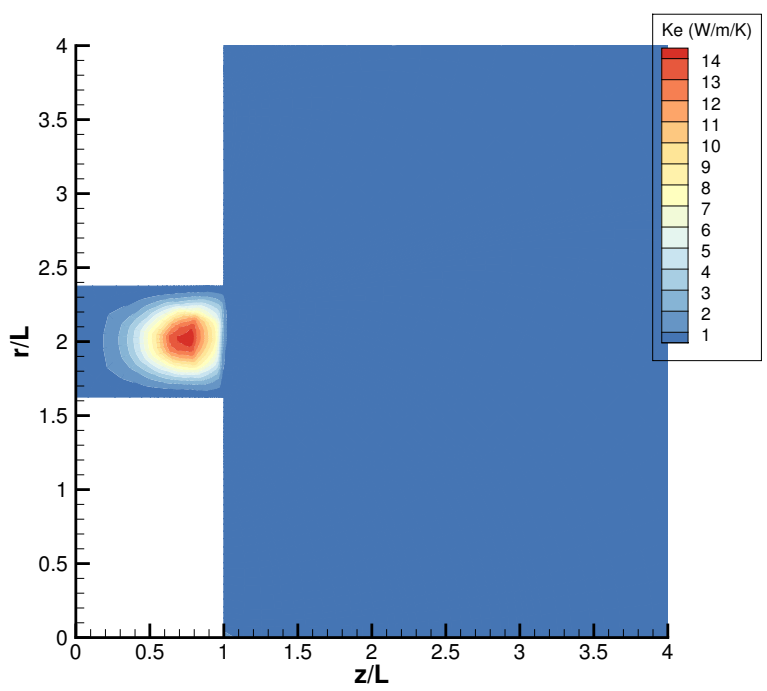

(a) Xenon $\dot{m}=19.7 \mathrm{mg} / \mathrm{s}$.

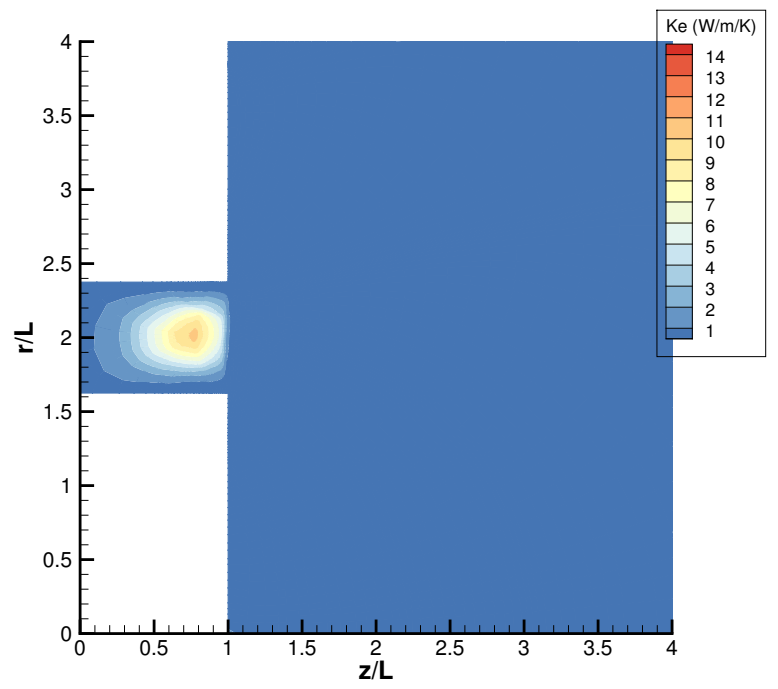

(b) Krypton, $\dot{m}=14.1 \mathrm{mg} / \mathrm{s}$.

Figure 10. Thermal conductivity magnitude. 


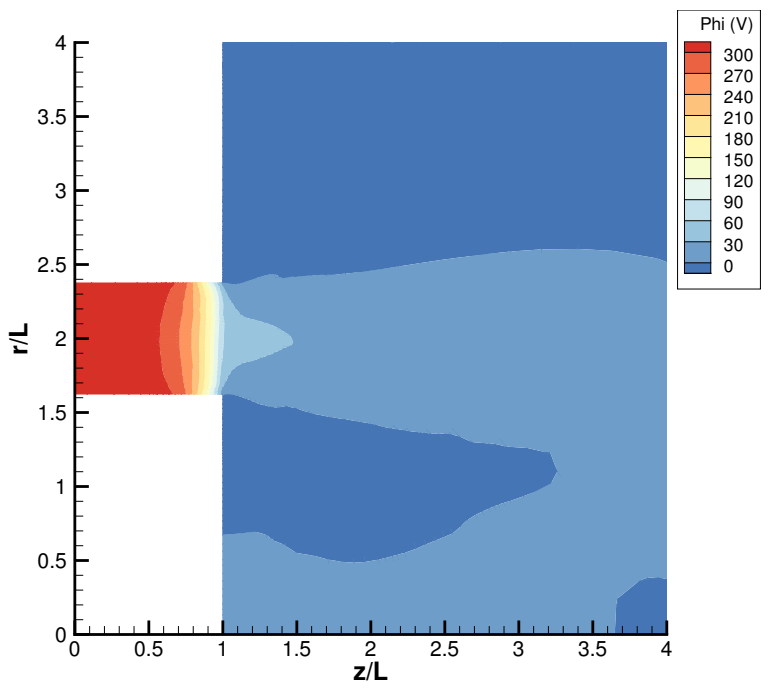

(a) Xenon $\dot{m}=19.7 \mathrm{mg} / \mathrm{s}$.

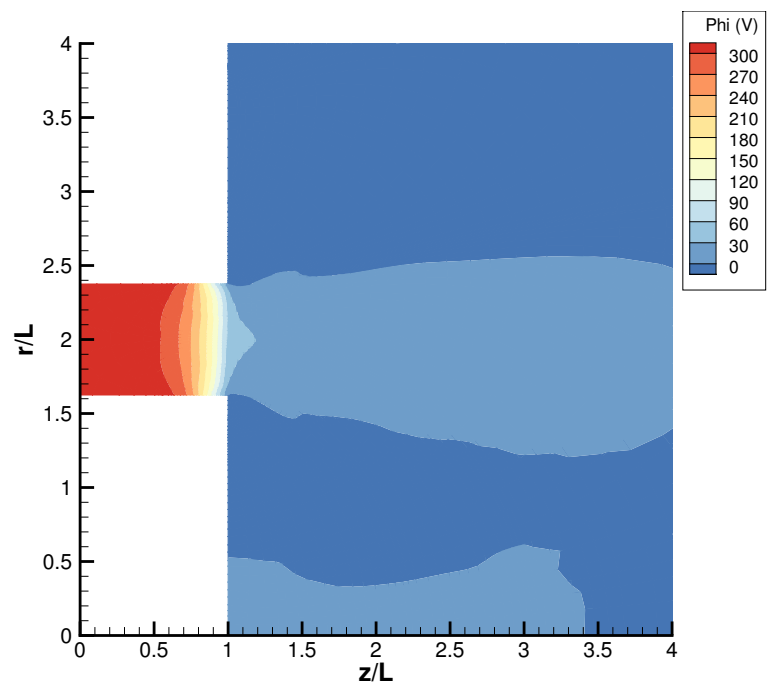

(b) Krypton, $\dot{m}=14.1 \mathrm{mg} / \mathrm{s}$.

Figure 11. Plasma potential.

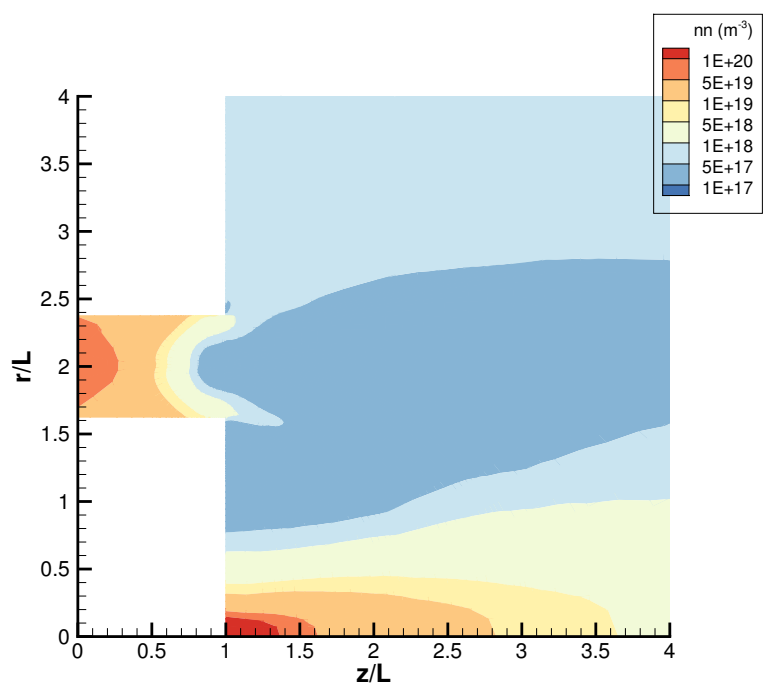

(a) Xenon $\dot{m}=19.7 \mathrm{mg} / \mathrm{s}$.

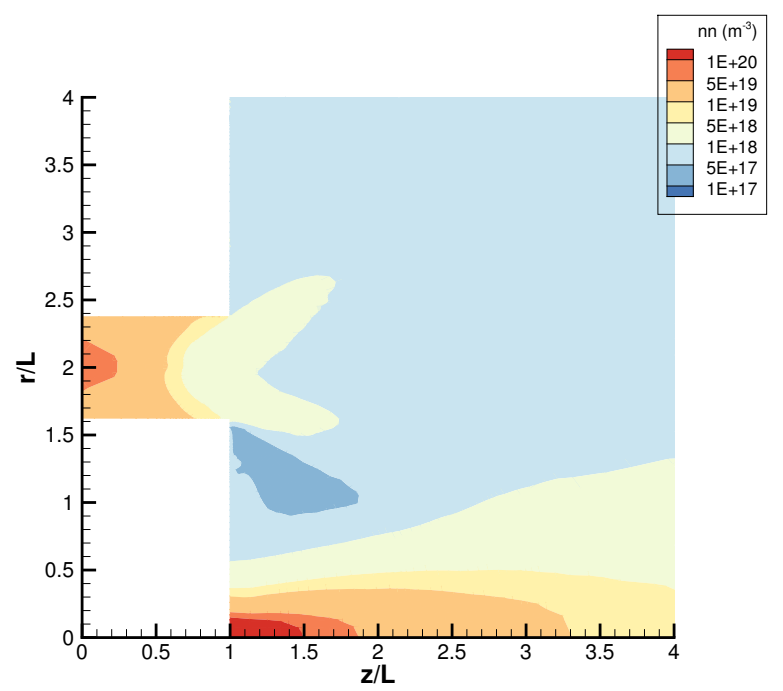

(b) Krypton, $\dot{m}=14.1 \mathrm{mg} / \mathrm{s}$.

Figure 12. Neutral number density. 


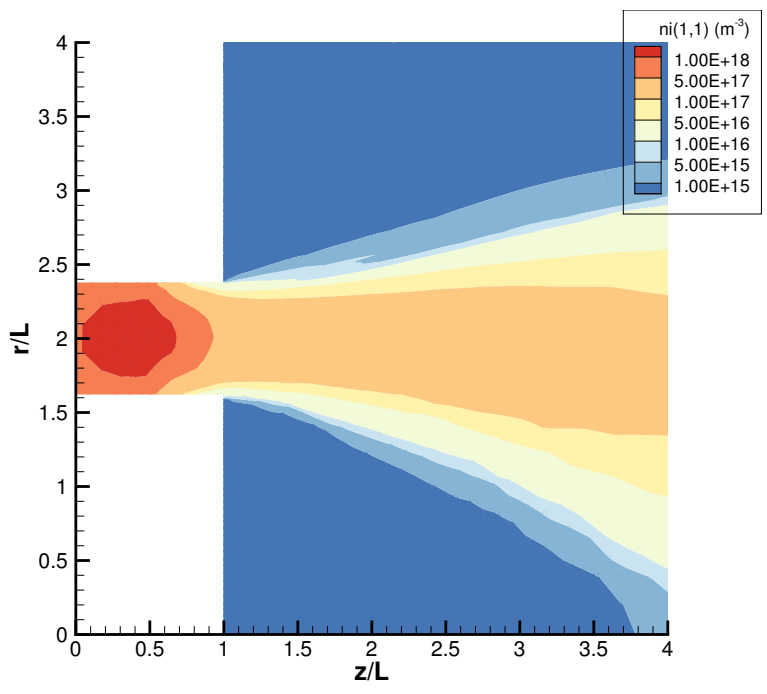

(a) Xenon $\dot{m}=19.7 \mathrm{mg} / \mathrm{s}$.

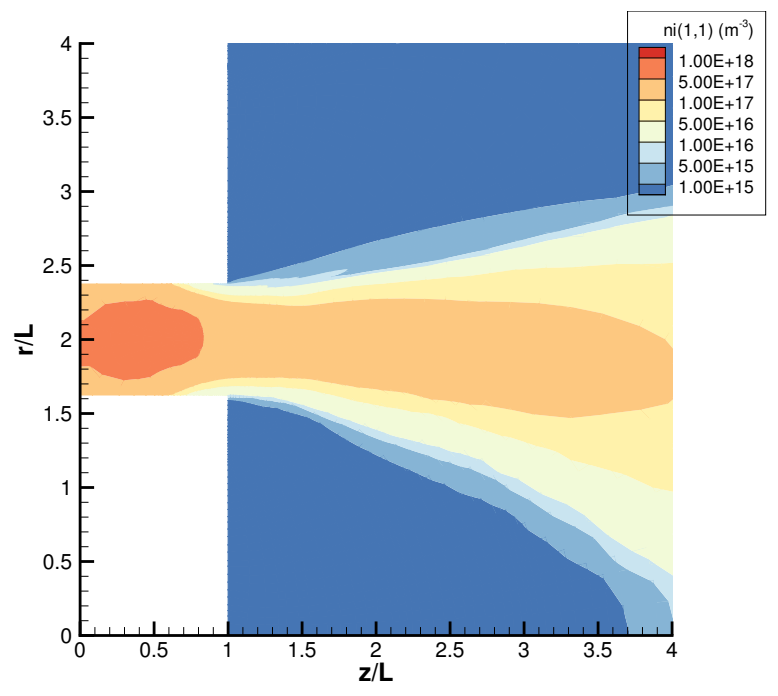

(b) Krypton, $\dot{m}=14.1 \mathrm{mg} / \mathrm{s}$.

Figure 13. Singly charged ion number density.

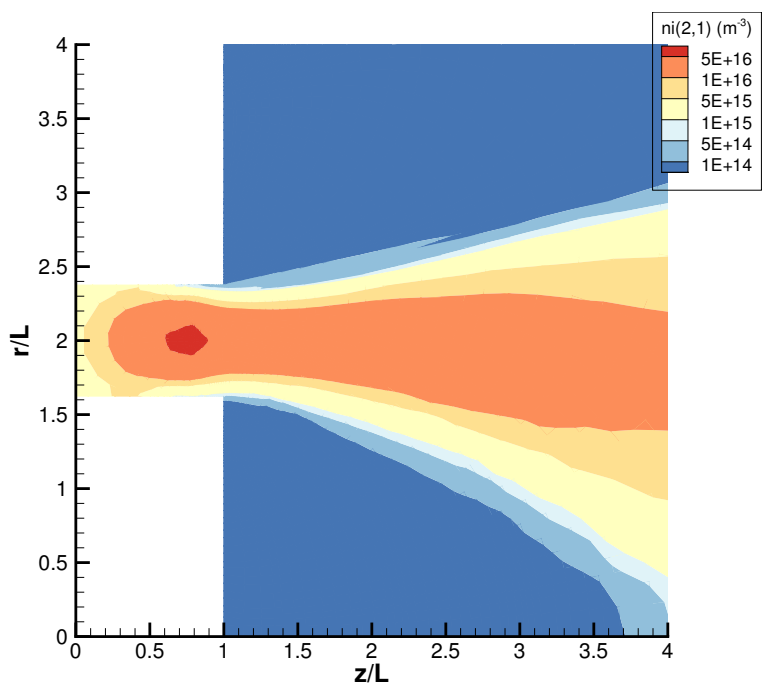

(a) Xenon $\dot{m}=19.7 \mathrm{mg} / \mathrm{s}$.

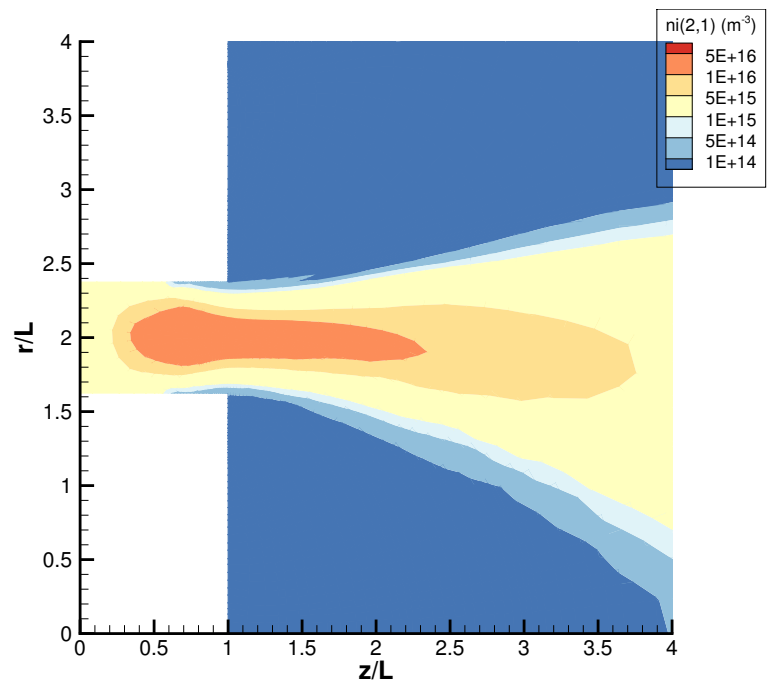

(b) Krypton, $\dot{m}=14.1 \mathrm{mg} / \mathrm{s}$.

Figure 14. Doubly charged ion number density. 


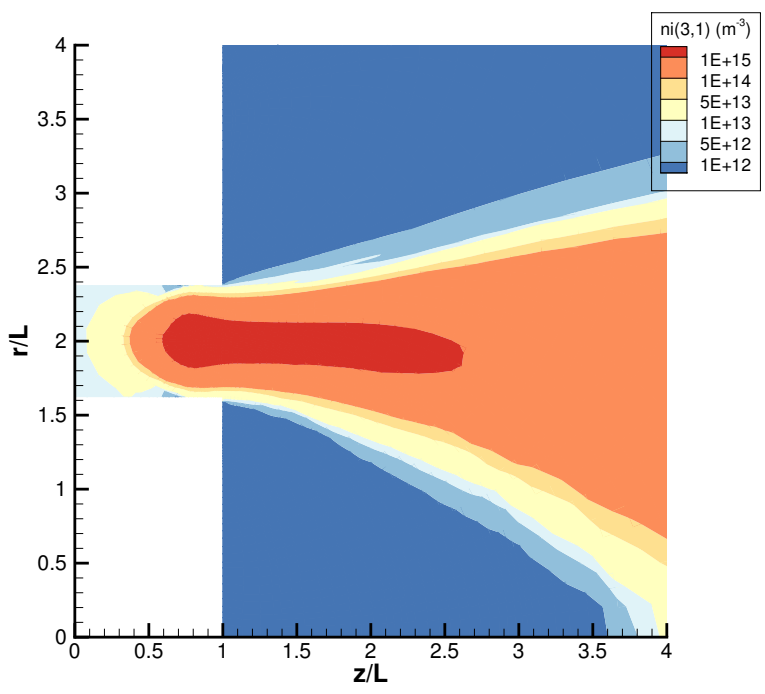

(a) Xenon $\dot{m}=19.7 \mathrm{mg} / \mathrm{s}$.

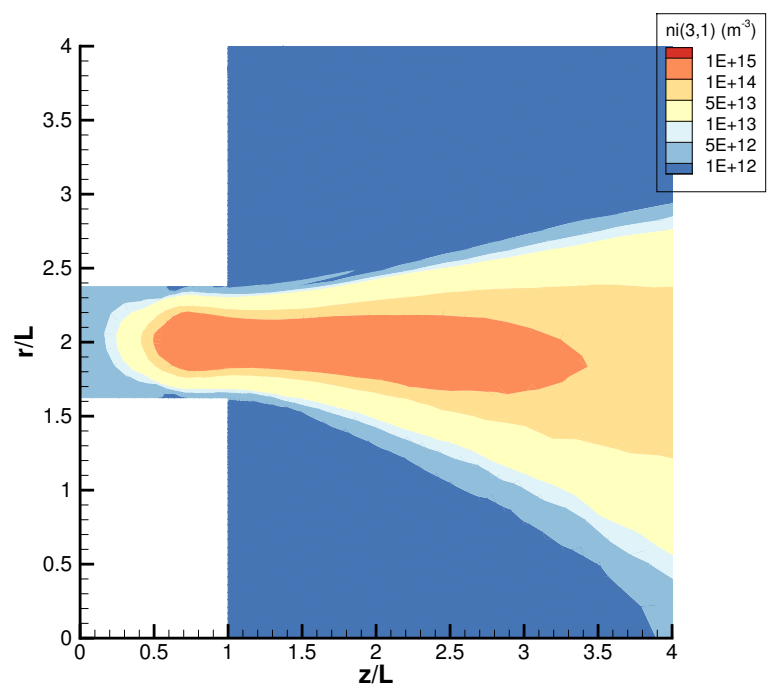

(b) Krypton, $\dot{m}=14.1 \mathrm{mg} / \mathrm{s}$.

Figure 15. Triply charged ion number density.

\section{Conclusion}

Krypton was incorporated as a propellant species in the Hall2De code, thus enabling further exploration of a less expensive alternative to the ubiquitous xenon gas that is currently being used for the majority of Hall effect thrusters. First, a back-of-the-envelope thruster performance calculation was presented to help evaluate the simulation results under the assumptions of a single charged species, and a mass efficiency value of unity. Next, a first series of simulations was performed on the NASA-300M thruster to validate the implementation by comparison with experimental data, and the thrust value was matched to within $10 \%$. Moreover, the trends observed in thrust and specific impulse matched the reduced order theoretical calculation. The thrust was $15 \%$ to $25 \%$ higher for the xenon propellant than krypton, while the prediction was $20 \%$. However, the krypton simulations produced specific impulse values between $10 \%$ and $16 \%$ higher than xenon cases, while the theoretical estimate was an increase of $25 \%$. The lower increase was observed because in computing the predicted value it was assumed that the thruster had a mass efficiency of one, and only singly charged ions, while in the simulation the efficiency value was lower, and three charged species were present.

Upon validating the krypton implementation with both the theoretical model and NASA-300M thruster, the next goal was to study the performance and plasma properties of krypton in an H6US thruster. Given the lack of experimental data for krypton operation, the numerical investigation began with a xenon test case. It was found that a $28.4 \%$ lower mass flow rate is required for krypton to reach the same $6 \mathrm{~kW}$ discharge power as the xenon case. Further, $13.3 \%$ higher specific was recorded when compared to xenon, and the thrust values obtained with krypton were lower by $19 \%$ than with xenon. While the percent difference in thrust was close to the theoretical estimate, the specific impulse increase in krypton was lower than expected, due to the presence of multiply charged species in the simulation which led to a lower mass flow rate for xenon (compared to the estimate), and thus a higher specific impulse. In addition, the ion current fractions for the two gases were compared, and the Hall2De results showed the expected trend, based on the difference in cross-sections. While the singly charged xenon current fraction was smaller than that of krypton, both higher charge states had higher fractions than krypton, and this behavior was also observed in the spatial distribution of ion number densities. Finally, the electron temperature was examined. While in the thruster channel Joule heating ensured that the two propellants produced a similar temperature distribution, once the electric field and current density began to diminish in the near-field plume, a faster decrease in temperature was observed for the krypton propellant. Considering the neutral and ion number density profiles, the likely cause for the temperature decrease were higher ionization losses for the krypton case. 
In summary, a simple theoretical model, and the simulation of two types of Hall effect thrusters have shown that the krypton species was successfully implemented in the Hall2De framework. It was found that the krypton ionization may occur farther downstream than for xenon. In addition, while the use of krypton propellant is expected to produce lower thrust than xenon, operating the thruster at the same power level will require a significantly lower flow rate, and produce a higher specific impulse.

\section{Future Work}

The results presented above may be improved by obtaining the precise magnetic field configuration for all the NASA-300M test points. In addition, electron temperature measurements for a thruster operating with krypton may improve our validation of the numerical results for other operating conditions. Furthermore, ion current fraction data would help validate the ionization model implemented in Hall2De.

The simulation of a thruster that was never run on krypton may be used to estimate mass savings before a potential laboratory test. This technique is illustrated in the present work for the H6US, and may be extended to other thrusters.

Finally, another direction for future research is to investigate the erosion rates on thruster pole pieces, the cathode, or for unshielded HETs, the channel walls. Due to lower ion densities in the near-field plume, one may expect to find lower erosion rates with a krypton propellant.

\section{Acknowledgments}

This work was supported by a NASA Space Technology Research Fellowship, grant number: NNX13AL51H. The authors appreciate the constructive comments and data provided by Dr. Yiangos Mikellides.

\section{References}

\footnotetext{
${ }^{1}$ Linnell, J. A. and Gallimore, A. D. Internal plasma potential measurements of a Hall thruster using xenon and krypton propellant, Physics of Plasmas, Vol. 3, 2006

${ }^{2}$ Linnell, J. A. and Gallimore, A. D. Efficiency Analysis of a Hall Thruster Operating with Krypton and Xenon, Journal of Propulsion and Power, Vol. 22, No. 6, 2006

${ }^{3}$ Nakles, M. R., et. al., "A Plume Comparison of Xenon and Krypton Propellant on a 600 W Hall Thruster", International Electric Propulsion Conference, IEPC-2009-115, Ann Arbor, MI, September 20-24, 2009.

${ }^{4}$ Garrigues, L., Boyd, I. D., and Boeuf, J. P. Computation of Hall Thruster Performance, Journal of Propulsion and Power, Vol. 17, No. 4, 2001

${ }^{5}$ Yim, J. T., "Computational Modeling of Hall Thruster Channel Wall Erosion," Ph.D. Dissertation, Dept. of Aerospace Engineering, University of Michigan, Ann Arbor, MI, 2008.

${ }^{6}$ Katz, I. and Mikellides, I. G., Neutral gas free molecular flow algorithm including ionization and walls for use in plasma simulations, Journal of Computational Physics, Vol. 230, pp. 1454-1464, 2011

${ }^{7}$ Mikellides, I. G. and Katz, I. Numerical simulations of Hall-effect plasma accelerators on a magnetic-field-aligned mesh, Physical Review E, Vol. 86, no. 4, 2012

${ }^{8}$ Lopez Ortega, A. and Mikellides, I. G., "A New Cell-Centered Implicit Numerical Scheme for Ions in the 2-D Axisymmetric Code Hall2De", AIAA/ASME/SAE/ASEE Joint Propulsion Conference E Exhibit, AIAA-2014-3621, Cleveland, OH, 28 July - 30 July, 2014.

${ }^{9}$ Boyd I. D., and Schwartzentruber T. E. Nonequilibrium Gas Dynamics and Molecular Simulation. Cambridge University Press; 2017 Mar 23.

${ }^{10}$ Yuan, J. and Zhang, Z., Low-energy electron scattering from Kr and Xe atoms, Journal of Physics B: At. Mol. Opt., Vol. 22, pp. 2581-2588, 1989

-11 Wagenaar, R. W. and de Heer, F. J., Total cross sections for electron scattering from Ar, Kr and Xe, Journal of Physics B: At. Mol. Opt., Vol. 18, pp. 2021-2036, 1985

$\checkmark{ }^{12}$ Nickel, J. C., Imre, K., Register, D. F., and Trajmar, S., Total electron scattering cross sections: I. He, Ne, Ar, Xe, Journal of Physics B: At. Mol. Phys., Vol. 18, pp. 125-133, 1985

${ }^{13}$ Register, D. F., Vuskovic, L., and Trajmar, S., Elastic electron scattering cross sections for Xe in the 1-100 eV impact energy region, Journal of Physics B: At. Mol. Phys., Vol. 19, pp. 1685-1697, 1986

$\checkmark{ }^{14}$ Wetzel, R. C., Baiocchi, F. A., Hayes T. R., and Freund, R. S., Absolute cross sections for electron-impact ionization of the rare-gas atoms by the fast-neutral-beam method, Physical Review A, Vol. 35, no. 2, 1987
} 
${ }^{15}$ Rejoub, R., Lindsay, B. G., and Stebbings, R. F., Determination of the absolute partial and total cross sections for electron-impact ionization of the rare gases, Physical Review A, Vol. 65, no. 042713, 2002

$\checkmark{ }^{16}$ Bell, E. W., Djuric, K., and Dunn, G. H., Electron-impact ionization of In+ and Xe+, Physical Review A, Vol. 48, no. 6, 1993

${ }^{17}$ Tinschert, K., Müller, A., Hofmann, G., Achenbach, C., Becker, R., and Salzborn, E. Electron impact single ionisation of multiply charged krypton ions, Journal of Physics B: At. Mol. Phys., Vol. 20, pp. 1121-1134, 1987

${ }^{18}$ Hause, M. L., Prince, B. J., and Bemish, R. J. Krypton charge exchange cross sections for Hall effect thruster models, Journal of Applied Physics, Vol. 113, 163301, 2013

${ }^{19}$ Kamhawi, H., et. al., "Performance Evaluation of the NASA-300M $20 \mathrm{~kW}$ Hall Effect Thruster", AIAA/ASME/SAE/ASEE Joint Propulsion Conference \& Exhibit, AIAA-2011-5521, San Diego, CA, 31 July - 03 August, 2011.

${ }^{20}$ Mikellides, I. G., et. al., "Numerical Simulations of a 20-kW Class Hall Thruster Using the Magnetic-Field-Aligned-Mesh

Code Hall2De", International Electric Propulsion Conference, IEPC-2011-244, Wiesbaden, Germany, September 11 - $15,2011$.

${ }^{21}$ Mikellides, I. G., et al. Magnetic shielding of the channel walls in a Hall plasma accelerator, Physics of Plasmas, Vol. 18, doi: 10.1063/1.3551583, 2011

${ }^{22}$ Kamhawi, H., et. al., "Performance and Thermal Characterization of the NASA-300MS 20 kW Hall Effect Thruster", International Electric Propulsion Conference, IEPC-2013-444, Washington, D.C., October 6 - 10, 2013.

$\checkmark{ }^{23}$ Jorns, B. A., Goebel, D. M., and Hofer, R. R., "Plasma Perturbations in High-Speed Probing of Hall Thruster Discharge Chambers: Quantification and Mitigation", AIAA/ASME/SAE/ASEE Joint Propulsion Conference ES Exhibit, AIAA-20154006, Orlando, FL, 31 July 27 - 28, 2015.

${ }^{24}$ Haas, J. M., Hofer, R. R., Brown, D. L., Reid, B. M. and Gallimore, A. D., "Design of the \#\# Hall Thruster for High Thrust/Power Investigation," 54th JANNAF Propulsion Meeting, Denver, CO, May 14-17, 2007.

${ }^{25}$ Reid, B. M., Gallimore, A. D., Hofer, R. R., Li, Y. and Haas, J. M., "Anode Design and Verification for the \#\# Hall Thruster," 54th JANNAF Propulsion Meeting, Denver, CO, May 14-17, 2007.

${ }^{26}$ Brown, D. L., Reid, B. M., Gallimore, A. D., Hofer, R. R., Haas, J. M., et al., "Performance Characterization and Design Verification of the \#\# Laboratory Model Hall Thruster," 54th JANNAF Propulsion Meeting, Denver, CO, May 14-17, 2007

${ }^{27}$ Reid, B. M. and Gallimore, A. D., "Plasma Potential Measurements in the Discharge Channel of a 6-kW Hall Thruster", AIAA/ASME/SAE/ASEE Joint Propulsion Conference 83 Exhibit, AIAA-2008-5185, Hartford, CT., July 21 - $23,2008$.

$\checkmark{ }^{28}$ Mikellides, I. G., Katz, I., and Hofer, R. R., "Design of a Laboratory Hall Thruster with Magnetically Shielded Channel Walls, Phase I: Numerical Simulations", AIAA/ASME/SAE/ASEE Joint Propulsion Conference E3 Exhibit, AIAA 2011-5809, San Diego, CA, July 31 - August 03, 2011.

$\checkmark{ }^{29}$ Hofer, R. R., Goebel, D. M., Mikellides, I. G., and Katz, I. "Design of a Laboratory Hall Thruster with Magnetically Shielded Channel Walls, Phase II: Experiments", AIAA/ASME/SAE/ASEE Joint Propulsion Conference E Exhibit, AIAA 2012-3788, Atlanta, GA, July 30 - August 01, 2012.

${ }^{30}$ Mikellides, I. G., Katz, I., Hofer, R. R., and Goebel, D. M. "Design of a Laboratory Hall Thruster with Magnetically Shielded Channel Walls, Phase III: Comparison of Theory with Experiment", AIAA/ASME/SAE/ASEE Joint Propulsion Conference Es Exhibit, AIAA 2012-3789, Atlanta, GA, July 30 - August 01, 2012.

- ${ }^{31}$ Mikellides, I. G., and Lopez Ortega, A. "Assessment of Pole Erosion in a Magnetically Shielded Hall Thruster", AIAA/ASME/SAE/ASEE Joint Propulsion Conference \&S Exhibit, AIAA 2014-3897, Cleveland, OH, July 28 - $30,2014$.

${ }^{32}$ Hargus Jr, William, Gregory M. Azarnia, and Michael R. Nakles. Comparison of Medium Power Hall Effect Thruster Ion Acceleration for Krypton and Xenon Propellants. No. AFRL-RQ-ED-JA-2013-137. AFRL/RQRS Edwards AFB United States, 2016. 